\title{
Parry-Romberg Syndrome: A Case Study of Two Patients
}

\author{
${ }^{1}$ Manish Chandra, ${ }^{2}$ Shikhar Saxena
}

\begin{abstract}
Introduction: Parry-Romberg syndrome is a rare neurocutaneous disorder, i.e., characterized by a slow and progressive atrophy of facial tissues, including muscles, bones, and skin of one or occasionally both sides of the face. Atrophy may be preceded by cutaneous discoloration of the affected skin, such as hyperpigmentation or depigmentation.
\end{abstract}

Observation: A 30-year-old female patient came with a chief complaint of progressive deformity of left-side face since 7 to 8 years. Progressive atrophy on left half face was noticed first at the age of 23 years as an area of hyperpigmentation on left malar region, which progressed with atrophy of the underlying fat and subcutaneous tissue resulting in disfigurement. Head and neck examination confirmed the asymmetry with flattening and hyperpigmentation on left side of face. There was an evident loss of underlying fat, muscle, and subcutaneous tissue giving a sunken appearance. Computed tomography scan revealed generalized atrophy of the soft tissue of the left hemi face resulting in asymmetry on the left side with deviated nasal septum. Another female patient of 35 years old came to the Department of Otorhinolaryngology with marked facial asymmetry on right side.

Conclusion: Two cases of PRS from different families are discussed. A 30-year-old female who presented with chief complaints of left side hemifacial atrophy and blackish pigmentation of overlying skin whose clinical features were consistent with PRS and a 35-year-old female with right-sided facial hemifacial atrophy.

Keywords: Parry-Romberg Syndrome, Progressive hemifacial atrophy, Rare.

How to cite this article: Chandra M, Saxena S. ParryRomberg Syndrome: A Case Study of Two Patients. Clin Rhinol An Int J 2017;10(1):14-16.

\section{Source of support: Nil}

Conflict of interest: None

\section{INTRODUCTION}

Parry-Romberg Syndrome (PRS), also referred to as progressive hemifacial atrophy, was first described by

\footnotetext{
${ }^{1}$ Assistant Professor, ${ }^{2}$ Resident

1,2Department of ENT, ERA's Lucknow Medical College and Hospital, Lucknow, Uttar Pradesh, India

Corresponding Author: Shikhar Saxena, Resident, Department of ENT, ERA's Lucknow Medical College and Hospital, Lucknow Uttar Pradesh, India, Phone: +918795903665, e-mail: shikhy79@gmail.com
}

Caleb Hillier Parry in 1825, and later in more detail by Moritz Heinrich Romberg in $1846 .{ }^{1,2}$ It is a rare neurocutaneous disorder, i.e., characterized by a slow and progressive atrophyof facial tissues, including muscles, bones, and skin of one or occasionally both sides of the face. ${ }^{3,4}$ The PRS commonly affects dermatomes of one or multiple branches of the trigeminal nerve. ${ }^{5}$ Atrophy may be preceded by cutaneous discoloration of the affected skin, such as hyperpigmentation or depigmentation. ${ }^{6}$ The other important features of this pathology are the enophthalmy, the deviation of mouth and nose to the affected side, and unilateral exposition of teeth, when lips are involved. Trauma, viral infections, endocrine disturbances, autoimmunity, and heredity are believed to be associated with the pathogenesis of the disease. ${ }^{8}$ The PRS has a prevalence rate of 1 in 70,000 of general population, affecting mainly females and usually left side of the face. ${ }^{1}$ We here report two cases of PRS from different families - a 30-year-old female who presented with chief complaints of left side hemifacial atrophy and blackish pigmentation of overlying skin whose clinical features were consistent with PRS and a 35-year-old female with right-sided facial hemifacial atrophy.

\section{CASE REPORT}

A 30-year-old female patient was referred to Department of Otorhinolaryngology, ERA's Lucknow Medical College and Hospital, Lucknow, Uttar Pradesh, India, with a chief complaint of progressive deformity of left side of the face since 7 to 8 years. Progressive atrophy on left half face was noticed first at the age of 23 years as an area of hyperpigmentation on left malar region, which progressed with atrophy of the underlying fat and subcutaneous tissue resulting in disfigurement. The patient's medical and family history was noncontributory. The patient had not sought any consultation earlier for facial disfigurement. On general examination, patient was conscious, oriented, afebrile, general condition was fair, and vitals were stable. Right side of the face appeared to be normal with marked facial asymmetry noted on left side. Head and neck examination confirmed the asymmetry with flattening and hyperpigmentation on left side of face. There was an evident loss of underlying fat, muscle, and subcutaneous tissue giving a sunken appearance (Figs 1A and B). Ocular examination and skin examination showed no abnormality with 


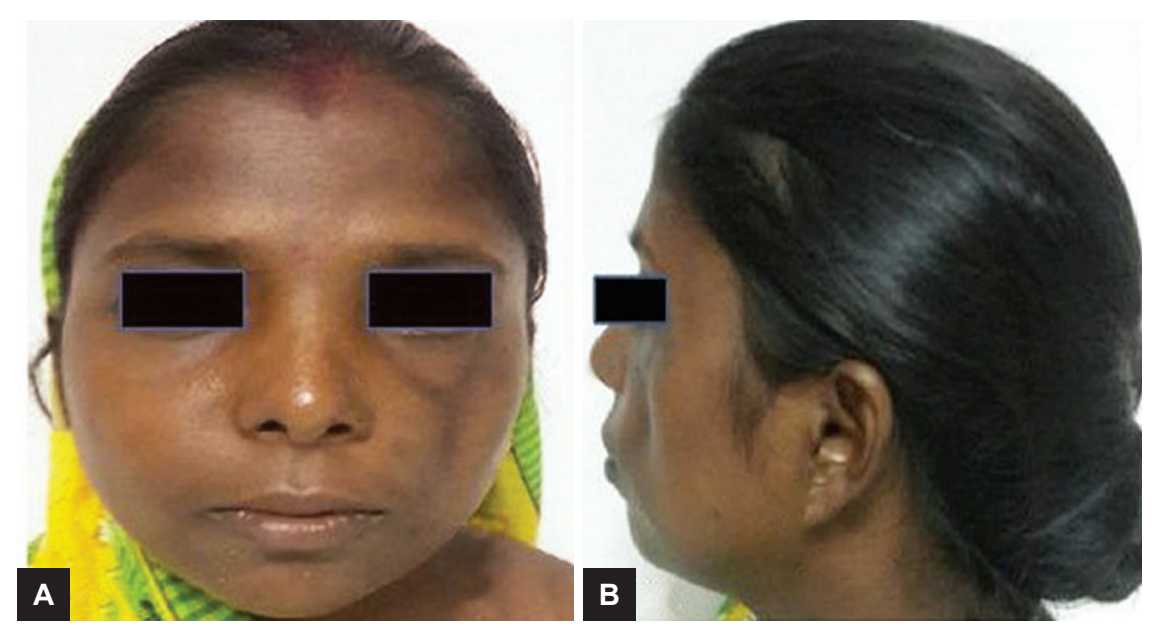

Figs $1 \mathrm{~A}$ and $\mathrm{B}$ : Front and lateral clinical profile picture of patient 1 showing facial asymmetry on left side
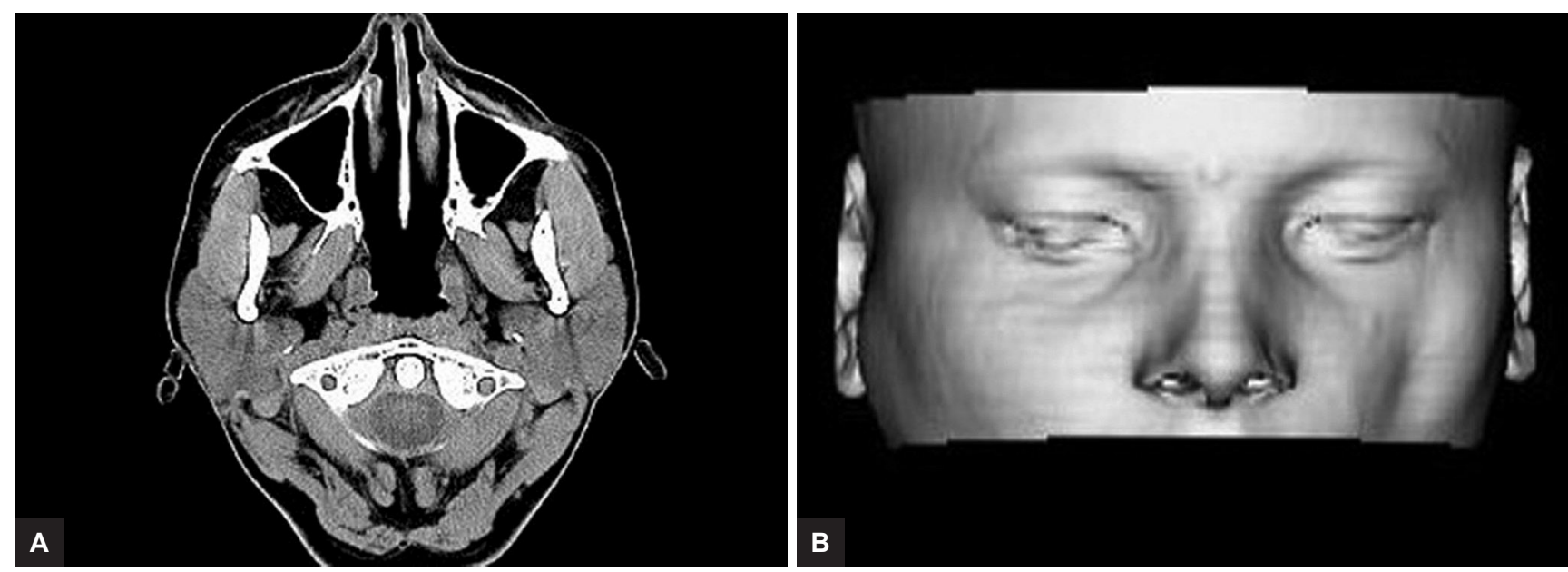

Figs 2A and B: Computed tomography scan revealed generalized atrophy of the soft tissue of the left hemiface resulting in asymmetry on the left side with left deviated nasal septum

any clinical regional lymphadenopathy. Examination of relevant cranial nerves revealed no obvious abnormality with normal vision, smell, and skin sensation on affected side of the face. Intraoral examination did not reveal any dental or soft tissue defects. Her routine hemogram report was within normal limit, patient was negative for antinuclear antibodies suggesting absence of any autoimmune disease. Computed tomography scan revealed generalized atrophy of the soft tissue of the left hemiface resulting in asymmetry on the left side with left deviated nasal septum (Figs 2A and B). Another female patient of 35 years old came to the Department of Otorhinolaryngology with marked facial asymmetry on right side (Figs 3 A and B). Diagnosis of PRS was made on basis of clinical features. After informed and written consent, we had given five doses of intralesional triamcinolone (corticosteroid) every month, and we have seen improvement in hyperpigmentation and facial atrophy. In second patient, the same treatment was advised, but she did not follow.

\section{DISCUSSION}

The diagnosis of PRS is based on the clinical manifestations of the disease. The condition has a prevalence rate of 1 in 70,000 of general population affecting mainly females and usually involves the left side of the face. ${ }^{1,2}$ More than an aesthetic concern, this disease brings several functional and psychological problems due to asymmetry of the face. Main feature is hemiatrophy of the facial tissues, typically fat, but variably skin, and other connective tissue. All these features are present in our case. When the condition commences after age of 15 years, the lesions are considered to be appearing exclusively in soft tissues. ${ }^{9}$ In the first case, patient reported the onset of the facial discoloration at the age of 22 without no facial deformity, which rapidly progressed to the present facial deformity. Uniqueness of our case is being late in onset; it affected the upper facial skeleton rather than the lower one-third.

The differential diagnosis includes hemifacial microsomia (first and second branchial arch syndrome) and its variant, such as Goldenhar syndrome, but these are 


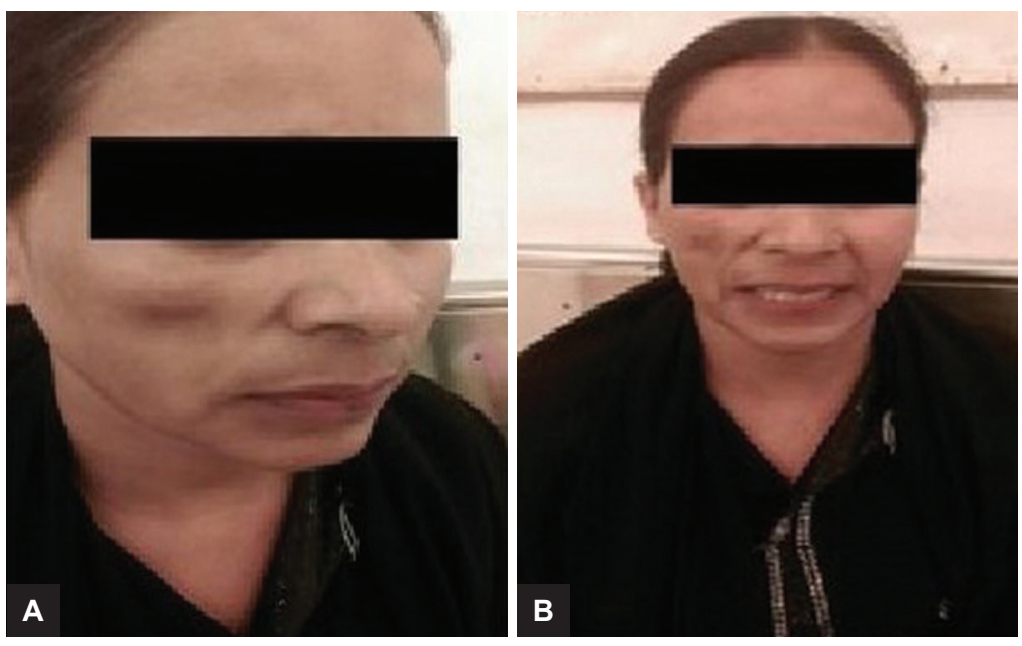

Figs $3 A$ and B: 35-years-old female patient with marked facial asymmetry on right side

congential and essentially nonprogressive conditions. Posttraumatic atrophy and partial lipodystrophy (BarraquerSimons syndrome) are also included in the differential diagnosis. However, partial lipodystrophy is usually bilateral and involves primarily the adipose tissue. ${ }^{10}$

The first patient under study had following features characteristic of PRS:

- Sex, mainly females

- Late in onset

- Progressive left side hemifacial atrophy appearing as asymmetry of face

- Hyperpigmentation

Second patient in the study also had hemifacial atrophy, but it was on the right side. Both patients were treated with intralesional triamcinolone, and improvement was found in first patient in hyperpigmentation and hemifacial atrophy after 5 doses every 3 weeks; the second patient did not follow up.

\section{CONCLUSION}

Two cases of PRS with its typical features, are discussed. Many patients present with classic clinical features, and there is little complexity in diagnosis of progressive hemifacial atrophy. Proper diagnosis and multidisciplinary treatment approach is essential for management of progressive hemifacial atrophy. Intralesional triamcinolone might be considered in some patients for improvement in hyperpigmentation and facial atrophy, but this is not the line of treatment. The cosmetic treatment is just recommended when illness stops its evolution, so this is the reason why our patient has not been submitted to any surgical intervention yet. More patients need to be followed up for standardizing the treatment protocol.

\section{REFERENCES}

1. Deshingkae SA, Barpande SR, Bhavthankar JD, Hume JE. Progressive hemifacial atrophy (Parry-Romberg Syndrome). Contemp Clin Dent 2012 Apr;3(5):S78-S81.

2. Sande A, Risbud M, Kshar A, Paranjpe AO. Progressive hemifacial atrophy. Dent Res J (Isfahan) 2013 Jan-Feb;10(1):108-111.

3. Taylor HM, Robinson R, Cox T. Progressive facial hemiatrophy: MRI appearances. Dev Med Child Neurol 1997 Jul;39(7):484-486.

4. Goldberg-Stern H, deGrauw T, Passo M, Ball WS Jr. ParryRomberg syndrome: follow-up imaging during suppressive therapy. Neuroradiology 1997 Dec;39(12):873-876.

5. Jurkiewicz MJ, Nahai F. The use of free revascularized grafts in the amelioration of hemifacial atrophy. Plast Reconstr Surg 1985 Jul;76(1):44-55.

6. Jappe U, Hölzle E, Ring J. Parry-Romberg syndrome. Summary and new knowledge based on an unusual case. Hautarzt 1996 Aug;47(8):599-603.

7. Whyman RA, Doyle TCA, Harding WJ, Ferguson MM. An unusual case of hemifacial atrophy. Oral Surg Oral Med Oral Pathol 1992 May;73(5):564-569.

8. Mazzeo N, Fisher JG, Mayer MH, Mathieu GP, Mcade FGG. Progressive hemifacial atrophy (Parry Romberg Syndrome). Oral Surg Oral Med Oral Pathol Oral Radiol Endod 1995 Jan;79(1):30-35.

9. Moore MH, Wong KS, Proudman TW, David DJ. Progressive hemifacial atrophy (Romberg's disease): skeletal involvement and treatment. Br J Plast Surg 1993 Jan;46(1):39-44.

10. Pensler JM, Murphy GF, Muliken JB. Clinical and ultrastructural studies of Romberg's hemifacial atrophy. Plast Reconstr Surg 1990 May;85(5):669-676. 